\title{
Vasoactive-inotropic score after pediatric heart transplant: A marker of adverse outcome
}

Sanil Y, Aggarwal S. Vasoactive-inotropic score after pediatric heart transplant: A marker of adverse outcome.

Abstract: VIS, a quantitative index of pressor support, has been shown to be a predictor of morbidity and mortality in infants younger than six months who underwent CPB. Data on its prognostic utility following pediatric OHT are lacking. This study compared clinical outcomes in children with differential VIS after pediatric OHT. A retrospective cohort study of 51 consecutive heart transplants from 2004 to 2011 was performed at a pediatric tertiary care facility. Peak VIS was computed within initial 24 and $48 \mathrm{~h}$ after OHT and was weighted for peak dose and administration of any or all of six pressors. Patients with peak VIS $\geq 15$ constituted high VIS group. Children who persistently required a higher magnitude of pressor support for the first $48 \mathrm{~h}$ after OHT, as reflected by high peak VIS, had significantly longer ICU stay (30.2 vs. 15.9 days, $p=0.01)$, pressor $(11.4$ vs. 6.8 days, $p=0.02)$ and ventilatory durations (12.4 vs. 5.9 days, $\mathrm{p}=0.05)$, and higher rates of short-term morbidities. Patients with longer CPB (213 vs. 153 min, $\mathrm{p}=0.005$ ) time have higher peak VIS. High peak VIS at $48 \mathrm{~h}$ is an effective, yet simple clinical marker for adverse outcomes in pediatric OHT recipients.

\author{
Yamuna Sanil and Sanjeev Aggarwal \\ Division of Pediatric Cardiology, Carmen and Ann \\ Adams Department of Pediatrics, The Children's \\ Hospital of Michigan, Wayne State University \\ School of Medicine, Detroit, MI, USA
}

Key words: pediatric heart transplant - vasoactive-
inotropic score - postoperative outcome - cardiac
surgery - congenital heart disease
Yamuna Sanil, MD, Division of Pediatric Cardiology,
The Children's Hospital of Michigan, 3901 Beaubien
Blvd, Detroit, MI 48201, USA
Tel.: 248-808-4120
Fax: 313-993-0894
E-mail: ysanil@dmc.org
Accepted for publication 15 May 2013
Pediatric orthotopic heart transplantation is the therapeutic option of choice for children with end-stage congenital or acquired heart disease (1). Advancements in medical therapy, refinements in surgical techniques, and availability of mechanical circulatory support systems have resulted in higher post-transplant survival rates in recent decades (2-4). Despite this, early postoperative morbidity and mortality continue to be significant following pediatric OHT (5-7).

Currently, there is only limited use of early postoperative markers that reflect the clinical status of the individual patient as well as predict outcomes after pediatric cardiac surgery. Inotropic score is one such objective clinical tool. It was initially described by Wernovsky et al. to quantify the extent of circulatory support that neonates received after arterial switch operation (8). Since then, several studies have used inotropic score as a

\footnotetext{
Abbreviations: $\mathrm{CHD}$, congenital heart disease; $\mathrm{CPB}$, cardiopulmonary bypass; ECMO, extracorporeal membrane oxygenation; ICU, intensive care unit; OHT, orthotopic heart transplant; VIS, vasoactive-inotropic score.
}

measure of disease severity (9-11). More recently, a modification of this scoring system called the vasoactive-inotropic score (VIS) was validated as a predictor of outcome after pediatric cardiac surgery $(12,13)$. VIS is a quantitative index of pressor support and takes into consideration use of milrinone, norepinephrine, and vasopressin in addition to dopamine, dobutamine, and epinephrine. Gaies et al. showed that VIS was a predictor of morbidity and mortality in infants younger than six months who underwent CPB (12).

There are no data on the prognostic utility of VIS following pediatric OHT. The aim of our study was to compare clinical outcomes in groups of children with differential VIS after pediatric OHT. Our hypothesis was that a persistently high VIS in the initial $48 \mathrm{~h}$ post-OHT would be associated with higher morbidity and mortality, relative to a low VIS.

\section{Methodology}

This was a retrospective study conducted at a single center, Children's Hospital of Michigan. Approval for the study and for waiver of parental 
consent and subject assent was obtained from the Institutional Review Board at Wayne State University and research authorization from Children's Hospital of Michigan. The charts of all patients, $18 \mathrm{yr}$ or younger, who underwent OHT between 2004 and 2010 at our institution were reviewed. Demographic, clinical, and immediate postoperative outcome data were collected. Demographic data included age, gender, diagnosis, and list status at the time of OHT. Preoperative clinical data pertaining to requirement of inotropic support, mechanical ventilation, or mechanical circulatory support in the immediate pretransplant period were also collected. Intraoperative characteristics including surgical technique of OHT, CPB time, and graft ischemia time were abstracted. Implantation of the donor heart was performed orthotopically using the biatrial or the bicaval technique. Before being weaned off $\mathrm{CPB}$, patients were started on vasoactive medications by the attending anesthesiologist/surgeon. The graft ischemic time was defined in the study as the time interval between the application of aortic cross-clamp in the donor and the removal of aortic cross-clamp in the recipient. In our center, rewarming is started only after the aortic cross-clamp is removed. Hence, the ischemic time in this study only includes the cold ischemic phase with temperatures maintained below $30{ }^{\circ} \mathrm{C}$. In the postoperative period, patients received close hemodynamic monitoring in the pediatric ICU with pulse oximetry, central venous pressure, left atrial pressure, and arterial pressure.

Vasoactive infusions were titrated, changed, or discontinued at the discretion of the cardiothoracic surgeons and pediatric intensivists based on individual clinical scenarios. Initial choices for vasoactive medication were milrinone, dobutamine, and dopamine. Epinephrine, norepinephrine, and vasopressin were used as second-line vasoactive agents. The doses of all the vasoactive infusions were obtained from the flow sheets at three hourly intervals for up to $48 \mathrm{~h}$ post-transplant. VIS was calculated using the formula proposed by Gaies et al. (12).

VIS = dopamine $(\mathrm{mcg} / \mathrm{kg} / \mathrm{min})+$ dobutamine $(\mathrm{mcg} / \mathrm{kg} / \mathrm{min})+100 \times$ epinephrine $(\mathrm{mcg} / \mathrm{kg} / \mathrm{min})$ +100 norepinephrine $(\mathrm{mcg} / \mathrm{kg} / \mathrm{min})+10 \times$ milrinone $(\mathrm{mcg} / \mathrm{kg} / \mathrm{min})+10000 \times$ vasopressin (mUnits/kg/min)

The VISs that were attained at three hourly intervals during the first $24 \mathrm{~h}$ and between 24 $48 \mathrm{~h}$ post-transplant were computed. A VIS of 15 or above on two or more of eight readings was taken as high inotropic requirement (high VIS $24 \mathrm{~h}$ ). VIS of $<15$ at all time points of observation was considered to be low inotropic requirement (low VIS $24 \mathrm{~h}$ ). The cutoff of peak VIS of 15 was predetermined based on the fivegroup classification system proposed by Gaies and colleagues (12). According to the authors, a moderate cardiovascular support on admission to the ICU after congenital heart surgery typically includes vasoactive infusions at dosages that result in a VIS of approximately 15 . We required this cutoff to be exceeded on two or more occasions (representing 3-h period each) over $24 \mathrm{~h}$. Further analysis was performed comparing patients with persistent high VIS $(48 \mathrm{~h})$, defined as peak VIS $>15$ on two or more readings in each of the two 24-h periods $(0-23 \mathrm{~h}, 24$ $48 \mathrm{~h}$ after OHT), and all others, low VIS (48 h).

A standard protocol was followed for immunosuppression post-OHT. All patients received induction therapy with intravenous thymoglobulin for five days. High-dose methyl prednisolone was initiated intraoperatively and continued for a total of six doses. Maintenance immunosuppressive regimen included tacrolimus, mycophenolate mofetil, and tapering dose of oral steroids. Decisions regarding the immunosuppressive therapy were made by the attending transplant cardiologist.

The primary outcome variable for our study was the total length of ICU stay after OHT. Secondary outcome variables included post-transplant requirement of mechanical circulatory support, duration of mechanical ventilation, number of days on vasoactive infusions, acute renal failure necessitating renal replacement therapy, and death prior to initial discharge after OHT.

\section{Statistics}

All data were reported as mean and standard deviation (s.d.) for continuous variables and frequency (percent) for categorical variables. The two groups (high and low VIS $24 \mathrm{~h}$ and persistent high and low VIS $48 \mathrm{~h}$ ) were compared using independent sample t-test, Fisher's exact test, or chi-square test depending on the distribution of the data. Regression analysis was performed to examine the association between ICU stay and high VISs, after adjusting for potential confounders found to be significant on univariate analysis. Statistical analyses were performed using SPSS version 17 (SPSS Inc., Chicago, IL, USA).

\section{Results}

A total of 55 patients underwent OHT at our institution from January 2004 to December 2010. Of these, four patients were older than $18 \mathrm{yr}$ at 
the time of OHT and were excluded from the study. The median age at the time of OHT of our study cohort $(\mathrm{N}=51)$ was $1.3 \mathrm{yr}$ (range: $1 \mathrm{wk}-$ $17.9 \mathrm{yr})$. Of these, $25(49 \%)$ were males. Based on the listed ethnicity, $21(42 \%)$ were Caucasian, $26(51 \%)$ African American, one (2\%) Hispanic, and two $(4 \%)$ were Asian. The indication for OHT was CHD in $20(39 \%)$, cardiomyopathy in $29(57 \%)$, and tumor in two $(4 \%)$ patients. The list status was $1 \mathrm{~A}$ in $46(90 \%)$ patients at the time of OHT. Prior to OHT, mechanical circulatory support was required in $13(26 \%)$ patients, of which nine were on left ventricular assist device and four on ECMO.In the pretransplant period, $14(28 \%)$ patients were mechanically ventilated and $30(60 \%)$ required inotropic support. The computed VIS ranged from 3 to 48, with a median of 14 in the 0 - to $24-h$ period and 12 in the 24- to 48-h period after OHT.

\section{Initial 24 h post-OHT}

In the first $24 \mathrm{~h}$ after OHT, 28 (55\%) patients had peak VIS of 15 or more on two or more occasions and were categorized as high VIS $(24 \mathrm{~h})$ group. The $23(45 \%)$ patients, who had VIS of $<15$, comprised the low VIS ( $24 \mathrm{~h}$ ) group. On comparing the groups, the low VIS ( $24 \mathrm{~h})$ group tended to have a predominance of cardiomyopathy rather than CHD. Demographic data including age, gender, ethnicity, and list status at the time of OHT were similar among the groups (Table 1). Preoperative requirements of mechanical ventilation, inotropic support, or mechanical circulatory support were also not different between the groups.

Table 2 compares operative characteristics and outcome among the two groups. A biatrial approach was used for OHT in 22 patients each $(79 \%$ vs. $96 \%, \mathrm{p}=0.08)$ in the high and low VIS (24 h) groups, respectively. Children in the high VIS (24 h) group had significantly longer CPB time (188 $\mathrm{min})$ than those in the low VIS $(24 \mathrm{~h})$ group $(148 \mathrm{~min})(\mathrm{p}=0.03)$. The graft ischemia time was similar between the groups. The outcome variables including length of ICU stay, duration of mechanical ventilation, and duration of vasoactive therapy were not significantly different between the groups. Acute renal failure necessitating renal replacement therapy was diagnosed in six patients in the high VIS $(24 \mathrm{~h})$ group, compared with one patient in the low VIS (24 h) group, a difference that did not reach statistical significance $(\mathrm{p}=0.11)$. PostOHT ICU length of stay, death, and post-OHT ECMO all tended to be higher in the high VIS (24 h) group.
Table 1. Demographic and preoperative data of high and low vasoactive-inotropic score groups at $24 \mathrm{~h}$ after orthotopic heart transplant

\begin{tabular}{|c|c|c|c|}
\hline $\mathrm{N}(\%)^{*}$ & $\begin{array}{l}\text { High VIS }(24 \text { h) } \\
(\mathrm{N}=28)\end{array}$ & $\begin{array}{l}\text { Low VIS (24 h) } \\
(\mathrm{N}=23)\end{array}$ & p-value \\
\hline Age (yr) median (range) & $1.1(0.02-17.5)$ & $1.2(0.05-17.9)$ & 0.61 \\
\hline Male & $15(54 \%)$ & $10(44 \%)$ & 0.33 \\
\hline \multicolumn{4}{|l|}{ Ethnicity } \\
\hline Caucasian & $10(36 \%)$ & $11(48 \%)$ & \multirow[t]{4}{*}{0.39} \\
\hline African American & $15(53 \%)$ & $11(48 \%)$ & \\
\hline Hispanic & $1(4 \%)$ & $0(0 \%)$ & \\
\hline Asian & $2(8 \%)$ & $1(4 \%)$ & \\
\hline Status $1 \mathrm{~A}$ & $28(100 \%)$ & $21(92 \%)$ & 0.47 \\
\hline \multicolumn{4}{|l|}{ Diagnosis } \\
\hline CHD & $14(50 \%)$ & $6(27 \%)$ & \multirow[t]{3}{*}{0.09} \\
\hline Cardiomyopathy & $14(50 \%)$ & $15(65 \%)$ & \\
\hline Tumor & $0(0 \%)$ & $2(8 \%)$ & \\
\hline $\begin{array}{l}\text { Preop mechanical } \\
\text { ventilation }\end{array}$ & $7(25 \%)$ & $7(30 \%)$ & 0.46 \\
\hline Preop inotropic therapy & $17(60 \%)$ & $13(56 \%)$ & 0.49 \\
\hline Preop LVAD/ECMO & $9(32 \%)$ & $4(18 \%)$ & 0.46 \\
\hline
\end{tabular}

*Value expressed as number (percentage).

$\mathrm{CHD}$, congenital heart disease; ECMO, extracorporeal membrane oxygenator; LVAD, left ventricular assist device; OHT, orthotopic heart transplant; Preop, preoperative; VIS, vasoactive-inotropic score.

Table 2. Comparison of intra-operative and outcome variables - $24 \mathrm{~h}$ after orthotopic heart transplant

\begin{tabular}{|c|c|c|c|}
\hline Mean ( \pm s.d.) or $n(\%)$ & $\begin{array}{l}\text { High VIS (24 h) } \\
(\mathrm{N}=28)\end{array}$ & $\begin{array}{l}\text { Low VIS (24 h) } \\
(\mathrm{N}=23)\end{array}$ & $\mathrm{p}$-value \\
\hline Graft ischemia time (min) & $191( \pm 56)$ & $195( \pm 43)$ & 0.76 \\
\hline CPB time (min) & $188( \pm 79)$ & $148( \pm 52)$ & 0.03 \\
\hline Biatrial technique & $22(78 \%)$ & $22(95 \%)$ & 0.08 \\
\hline Intensive care unit stay (days) & $24( \pm 22.5)$ & $15.4( \pm 10.8)$ & 0.09 \\
\hline Mechanical ventilation (days) & $9.6( \pm 12.7)$ & $5.6( \pm 6.9)$ & 0.17 \\
\hline Vasoactive infusion (days) & $8.8( \pm 8)$ & $7.5( \pm 4.2)$ & 0.5 \\
\hline Post-op ECMO & $3(11 \%)$ & $1(5 \%)$ & 0.61 \\
\hline Acute renal failure & $6(21 \%)$ & $1(5 \%)$ & 0.11 \\
\hline Death & $3(11 \%)$ & $1(5 \%)$ & 0.61 \\
\hline
\end{tabular}

CPB, cardiopulmonary bypass; OHT, Post-op, postoperative; ECMO, extracorporeal membrane oxygenator; VIS, vasoactive-inotropic score.

\section{8 h post-OHT}

Between 24-48 h after OHT, 15 patients continued to require high dose of vasoactive infusions. These patients with a VIS of 15 or higher on two or more occasions in the 24 - to 48 -h postoperative period were categorized as persistent high VIS (48 h) group. The remaining 36 patients $(71 \%)$ who had peak VIS $<15$ between 24 and $48 \mathrm{~h}$ after OHT constituted the low VIS (48 h) group. All the patients with a low VIS in the first $24 \mathrm{~h}$ post-OHT continued to require low inotropic support in the subsequent $24 \mathrm{~h}$.

On comparing the persistent high VIS (48 h) group with low VIS (48 h) group (Table 3 ), the only significant difference was that in the 
persistent high VIS (48 h) group, $67 \%$ of patients underwent OHT for CHD compared with $27 \%$ of the patients in the low VIS (48 h) group $(p=0.01)$. Preoperative requirement of mechanical ventilation, inotropic support, or mechanical circulatory support was not different between the groups.

Comparison of the operative and outcome data is detailed in Table 4. Biatrial technique was used for OHT in the majority of patients in both groups. Patients in the persistent high VIS $(48 \mathrm{~h})$ group had significantly longer CPB time $(213[ \pm 83]$ vs. $153[ \pm 57], \mathrm{p}=0.005)$. The persistent high VIS $(48 \mathrm{~h})$ group patients required longer duration of vasoactive infusion therapy $(p=0.02)$, post-OHT ICU stay $(p=0.01)$, and higher rate of renal failure $(\mathrm{p}<0.001)$, compared with low VIS (48 h) group. Three patients in the persistent high VIS (48 h) group and one patient in the low VIS (48 $\mathrm{h}$ ) group required ECMO support after OHT. This difference was not statistically significant.

The overall mortality rate in the immediate post-transplant period was $7.8 \%$. Three $(20 \%)$ subjects in the persistent high VIS (48 h) group died compared with one $(4 \%)$ in the low VIS $(48 \mathrm{~h})$ group $(\mathrm{p}=0.08)$. Cause of death was sepsis in two patients and multiorgan dysfunction in the third patient in the persistent high VIS (48 h) group and postoperative bleeding in the patient in the persistent low VIS (48 h) group.

On regression analysis, with diagnosis (CHD vs. cardiomyopathy), CPB time, persistent high

Table 3. Demographic and preoperative data: persistent high and low vasoactive-inotropic score groups at $48 \mathrm{~h}$ after orthotopic heart transplant

\begin{tabular}{lccc}
\hline & $\begin{array}{l}\text { High VIS (48 h) } \\
\text { N (\%) }\end{array}$ & $\begin{array}{l}\text { Low VIS (48 h) } \\
(\mathrm{N}=36)\end{array}$ & p-value \\
\hline Age (yr) median (range) & $1.1(0.02-17.9)$ & $1.3(0.04-17.9)$ & 0.39 \\
Male & $7(47 \%)$ & $18(50 \%)$ & 0.53 \\
Ethnicity & & & \\
$\quad$ Caucasian & $5(33 \%)$ & $16(47 \%)$ & 0.37 \\
African American & $8(53 \%)$ & $18(50 \%)$ & \\
$\quad$ Hispanic & $1(7 \%)$ & $0(0 \%)$ & \\
Asian & $1(7 \%)$ & $1(3 \%)$ & \\
$\quad$ Status 1A & $14(93 \%)$ & $30(83 \%)$ & 0.76 \\
Diagnosis & & & \\
$\quad$ CHD & $10(67 \%)$ & $10(28 \%)$ & 0.01 \\
Cardiomyopathy & $5(33 \%)$ & $24(67 \%)$ & \\
Tumor & $0(0 \%)$ & $2(5 \%)$ & \\
Preop mechanical ventilation & $5(33 \%)$ & $9(25 \%)$ & 0.54 \\
Preop inotropic therapy & $11(73 \%)$ & $19(53 \%)$ & 0.17 \\
Preop LVAD/ECM0 & $4(26 \%)$ & $9(25 \%)$ & 0.07 \\
\hline
\end{tabular}

*Value expressed as number (percentage).

$\mathrm{CHD}$, congenital heart disease; ECMO, extracorporeal membrane oxygenator; LVAD, left ventricular assist device; OHT, orthotopic heart transplant; Preop, preoperative; VIS, vasoactive-inotropic score.
Table 4. Comparison of intra-operative and outcome variables-persistent high and low vasoactive-inotropic score groups at $48 \mathrm{~h}$ after orthotopic heart transplant

\begin{tabular}{|c|c|c|c|}
\hline Mean (s.d.) or n (\%) & $\begin{array}{l}\text { High VIS (48 h) } \\
(\mathrm{N}=15)\end{array}$ & $\begin{array}{l}\text { Low VIS (48 h) } \\
(\mathrm{N}=36)\end{array}$ & $\mathrm{p}$-value \\
\hline Graft ischemia time (min) & $200( \pm 56)$ & $189( \pm 48)$ & 0.48 \\
\hline CPB time (min) & $213( \pm 83)$ & $153( \pm 57)$ & 0.005 \\
\hline Biatrial technique & $12(80 \%)$ & $32(97 \%)$ & 0.4 \\
\hline Intensive care unit stay (days) & $30.2( \pm 27.4)$ & $15.9( \pm 11.3)$ & 0.01 \\
\hline Mechanical ventilation (days) & $12.4( \pm 15.7)$ & $5.9( \pm 10.2)$ & 0.05 \\
\hline Vasoactive infusion (days) & $11.4( \pm 9.8)$ & $6.8( \pm 3.8)$ & 0.02 \\
\hline Post-op ECMO & $3(20 \%)$ & $1(4 \%)$ & 0.07 \\
\hline Renal failure & $6(40 \%)$ & $1(3 \%)$ & $<0.001$ \\
\hline Death & $3(20 \%)$ & $1(4 \%)$ & 0.07 \\
\hline
\end{tabular}

CPB, cardiopulmonary bypass; Post-op, postoperative; ECMO, extracorporeal membrane oxygenator; VIS, vasoactive-inotropic score.

VIS at 48-h group, and mechanical circulatory support prior to OHT as covariates, ICU stay was significantly associated with persistent high VIS at 48 -h group $(\mathrm{p}=0.04)$. There was no significant association between ICU stay and any other variables. High VIS at $24 \mathrm{~h}$ was not significantly associated with length of ICU stay.

\section{Discussion}

In this study, we evaluated the association between VIS following OHT in children and short-term outcomes. Our study shows that persistently high VIS in the first $48 \mathrm{~h}$ after pediatric OHT is associated with short-term morbidities such as renal failure, increased post-OHT length of stay, and duration of pressor therapy. Although not statistically significant, death tended to be higher in those with persistent high VIS until $48 \mathrm{~h}$. High VIS as defined (more than 15 on $\geq 2$ times three $\mathrm{h}$ apart in $24 \mathrm{~h}$ ) was common $(55 \%)$ in the initial $24 \mathrm{~h}$ after OHT and does not appear to be associated with adverse outcomes. A third of subjects continued to require high dose of vasoactive agents in the subsequent $24 \mathrm{~h}$, high VIS (48 h) group. CHD was the predominant underlying indication for pediatric OHT in the persistent high VIS (48 h) group.

Vasoactive inotropic score was initially proposed by Gaies et al. (12). They evaluated 174 infants (age 0-6 months) undergoing cardiovascular surgery with $\mathrm{CPB}$ and concluded that the maximum VIS over the first $48 \mathrm{~h}$ after cardiac surgery was a good predictor of poor clinical outcome such as death, cardiac arrest, mechanical circulatory support, renal replacement, and/ or neurological injury. High VIS was strongly associated with poor outcomes and length of stay and duration of mechanical ventilation. 
Davidson et al., in a study on 70 infants ( $\leq 90$ days of age) undergoing cardiothoracic surgery found that a higher VIS at $48 \mathrm{~h}$ after cardiothoracic surgery was strongly associated with increased length of ventilation and prolonged ICU and total hospital stay (13). Their results also showed that high VIS at $48 \mathrm{~h}$ was better than VIS maximum in predicting short-term morbidity, suggesting that the duration, rather than the intensity of pressor support, may be a marker of adverse outcomes. Butts et al. studied low cardiac output syndrome and maximum VIS in neonates $(\mathrm{n}=76)$ undergoing cardiac surgery requiring $\mathrm{CPB}$ (14). They reported a moderate association of increasing VIS with longer duration of mechanical ventilation as well as ICU stay. Again maximum VIS did not correlate with the total hospital length of stay.

All these previous studies on VIS have been on neonates and infants up to 6 months of age. Our study cohort included all patients $<18 \mathrm{yr}$ of age at the time of transplant and had a median age of $1.4 \mathrm{yr}$. This is the first study to evaluate the prognostic utility of VIS following pediatric OHT.

We evaluated both the intensity of vasoactive therapy and the duration for which high-intensity therapy was required. Our study showed that high VIS in the initial $24 \mathrm{~h}$ was quite common after OHT, specifically in those with longer CPB time, but was not significantly associated with adverse short-term outcomes. We speculate that high requirement of vasoactive agents in the initial $24 \mathrm{~h}$ after OHT was probably due to the transient circulatory changes secondary to prolonged $\mathrm{CPB}$. In contrast, a persistent high VIS for $48 \mathrm{~h}$ may be a marker of worse underlying physiology. These findings are similar to those reported recently by other investigators. (12-14).

Children undergoing OHT for CHD tended to have high VIS (48 h) in this study. This goes along with the findings from previous studies as well (15-17). It has been shown that perioperative morbidity in patients with CHD undergoing OHT is higher when compared with patients with cardiomyopathy undergoing OHT. Reoperation, need for reconstructive procedures, high technical complexity of the surgical procedure, increased pulmonary vascular resistance, and allograft sensitization may all contribute to the higher postoperative severity of illness in these patients. Patients with CHD also have a significantly longer CPB time; however, neither diagnosis nor $\mathrm{CPB}$ time were independently associated with postoperative length of stay following OHT in our study.
Renal failure in the perioperative period has been shown to be associated with increased mortality and morbidity after OHT (18-20). Our data suggest that there is a higher occurrence of acute renal failure in patients persistently needing high vasoactive support in the initial $48 \mathrm{~h}$ after OHT. The association between high VIS and postoperative renal failure may have physiological plausibility - renal failure in this scenario is often prerenal related to hypoperfusion of the kidney. Further, renal failure may be a key factor in the pathway to adverse outcomes such as prolonged length of stay and death.

Persistent requirement of vasoactive agents as shown by high VIS (48 h) may likely be a surrogate marker of disease severity, rather than the cause of increased morbidity. However, there have been a few studies which show that use of vasopressin and dopamine in the immediate postoperative period is associated with poor short-term outcomes $(21,22)$.

The VIS is an objective measure of the level of inotropic support and therefore severity of illness. This tool may have potential utility in the comparison of VIS-adjusted outcomes across transplant centers for research and clinical improvement purposes. In addition, as a persistent high VIS at $48 \mathrm{~h}$ is associated with longer ICU stay and short-term adverse outcomes following OHT, it may be useful in counseling families at an early time point. It is possible that a high VIS, if validated in larger multicenter studies, may aid in risk stratification for future trials of therapeutic interventions in this population.

\section{Study limitations}

Our study is a retrospective review from a single institution. Even though the sample size was small, the pediatric OHT population is relatively rare but homogenous. Due to the retrospective nature, data collection depended on the extent of documentation in the medical records. The clinical management of patients was not protocoldriven and may have varied based on the judgment and practice of individual clinicians. Our retrospective study was not intended to investigate the causality between use of various vasoactive agents and short-term morbidity following OHT in children.

\section{Conclusion}

To our knowledge, this is the first study comparing outcomes of pediatric heart transplantation based on the post-transplant VIS. This study validates the use of VIS in pediatric OHT recipients. Persistent requirement of high doses of 
vasopressor and inotropes at $48 \mathrm{~h}$ post-OHT (high VIS $48 \mathrm{~h}$ ) is independently associated with increased short-term morbidity after pediatric OHT. Further prospective studies with stringent protocols for inotrope management are required to assess the role of VIS in predicting long-term outcome and to evaluate a causal relationship, if any, between high inotrope use and adverse outcomes including mortality.

\section{Authors' contributions}

Yamuna Sanil involved in data collection, analysis, and drafting of the article; Sanjeev Aggarwal contributed to concept/design, statistics, interpretation, and critical revision of the manuscript.

\section{Financial disclosures}

None.

\section{References}

1. Fricker FJ, Addonizio L, Bernstein D, et al. Heart transplantation in children: Indications. Pediatr Transplant 1999: 3: 333-342.

2. Kirk R, Edwards LB, Kuchereyavaya AY, et al. The Registry of the International Society for Heart and Lung Transplantation: Fourteenth official pediatric heart transplantation report-2011. J Heart Lung Transplant 2011: 10: 1095-1103.

3. Chen JM, Richmond ME, Charette $\mathrm{K}$, et al. A decade of pediatric mechanical circulatory support before and after cardiac transplantation. J Thorac Cardiovasc Surg 2012: 143: 344-351.

4. Milano CA, Shah AS, Van Trigt P, et al. Evaluation of early postoperative results after bicaval versus standard cardiac transplantation and review of literature. Am Heart J 2000: 140: 717-721.

5. Morales DL, Dreyer WJ, Denfield SW, et al. Over two decades of pediatric heart transplantation: How has survival changed? J Thorac Cardiovasc Surg 2007: 133: 632-639.

6. Zuppan CW, Wells LM, Kerstetter JC, Johnston JK, Bailey LL, CHINNOCK RE. Cause of death in pediatric and infant heart transplant recipients: Review of a 20-year, single-institution cohort. J Heart Lung Transplant 2009: 28: 579-584.

7. Tissot C, Buckvold S, Phelps CM, et al. Outcome of extracorporeal membrane oxygenation for early primary graft failure after pediatric heart transplantation. J Am Coll Cardiol 2009: 54: 730-737.

8. Wernovisky G, Wypij D, Jonas RA, et al. Postoperative course and hemodynamic profile after the arterial switch operation in neonates and infants: A comparison of low flow cardiopulmo- nary bypass and circulatory arrest. Circulation 1995: 92: 22262235.

9. Andreasen JB, Johnsen SP, Ravn HB. Junctional ectopic tachycardia after surgery for congenital heart disease in children. Intensive Care Med 2008: 34: 895-902.

10. Maarslet L, Moler MB, Dall R, Huortholm K, Ravn H. Lactate levels predict mortality and need for peritoneal dialysis in children undergoing congenital heart surgery. Acta Anaesthesiol Scand 2012: 56: 459-464.

11. Salvin JW, Scheurer MA, Laussen PC, et al. Factors associated with prolonged recovery after the fontan operation. Circulation 2008: 118: S171-S176.

12. Gaies MG, Gurney JG, Yen AH, et al. Vasoactive-inotropic score as a predictor of morbidity and mortality in infants after cardiopulmonary bypass. Pediatr Crit Care Med 2010: 11: 234238.

13. Davidson J, Tong S, Hancock H, Hauck A, Da Cruz E, Kaufman J. Prospective validation of the vasoactive-inotropic score and correlation to short-term outcomes in neonates and infants after cardiothoracic surgery. Intensive Care Med 2012: 38: 1184-1190.

14. Butts RJ, Scheurer MA, Altz AM, et al. Comparison of maximum vasoactive inotropic score and low cardiac output syndrome as markers of early postoperative outcomes after neonatal cardiac surgery. Pediatr Cardiol 2012: 33: 633-638.

15. Davies RR, Russo MJ, Mital S, et al. Predicting survival among high-risk pediatric cardiac transplant recipients: An analysis of the United Network for Organ Sharing database. J Thorac Cardiovasc Surg 2008: 135: 147-155.

16. Lamour JM, Kanter KR, Naftel DC, et al. The effect of age, diagnosis, and previous surgery in children and adults undergoing heart transplantation for congenital heart disease. J Am Coll Cardiol 2009: 54: 160-165.

17. Tuang YS, Stenlund H, Tenderich G, Hornik L, Bairaktaris A, Korfer R. Risk factor analysis in pediatric heart transplantation. J Heart Lung Transplant 2008: 27: 408-415.

18. Almond CS, Gauvreau K, Canter CE, Rajagopal SK, Piercey GE, Singh TP. A risk-prediction model for in-hospital mortality after heart transplantation in US children. Am J Transplant 2012: 12: 1240-1248.

19. TAng L, Du W, L'Ecuyer TJ. Perioperative renal failure in pediatric heart transplant recipients: Outcome and risk factors. Pediatr Transplant 2011: 15: 430-436.

20. Rajagopal SK, Yarlagadda VV, Thiagarajan RR, Singh TP, Givertz MM, Almond CS. Pediatric heart failure and worsening renal function: Association with outcomes after heart transplantation. J Heart Lung Transplant 2012: 31: 252-258.

21. Li J, Zhang G, Holtby H, Humpl T, et al. Adverse effects of dopamine on systemic hemodynamic status and oxygen transport in neonates after the Norwood procedure. J Am Coll Cardiol 2006: 48: 1859-1864.

22. Mastropietro CW, Clark JA, Delius Re, Walters hl 3rd, SARNAIK AP. Arginine vasopressin to manage hypoxemic infants after stage I palliation of single ventricle lesions. Pediatr Crit Care Med 2008: 9: 506-510. 